\title{
Macrolide-resistant Mycoplasma pneumoniae in adults with community acquired pneumonia: challenges and risks
}

\author{
Atousa Hakamifard ${ }^{1}$ and Ali Saffaei ${ }^{2}$
}

${ }^{1}$ Department of Infectious Diseases, School of Medicine, Isfahan University of Medical Sciences, Isfahan, Islamic Republic of Iran. ${ }^{2}$ Student Research Committee, Department of Clinical Pharmacy, School of Pharmacy, Shahid Beheshti University of Medical Sciences, Tehran, Islamic Republic of Iran. (Correspondence to: Atousa Hakamifard: a.hakamifard@med.mui.ac.ir).

Citation: Hakamifard A; Saffaei A. Macrolide resistant Mycoplasma pneumoniae in adults with community acquired pneumonia: challenges and risks. East Mediterr Health J. 2020;26(2):141-142 https://doi.org/10.26719/2020.26.2.141

Received: 01/11/19; accepted: 31/12/19

Copyright (c) World Health Organization (WHO) 2020. Open Access. Some rights reserved. This work is available under the CC BY-NC-SA 3.o IGO license (https://creativecommons.org/licenses/by-nc-sa/3.o/igo).

Sir,

Mycoplasma pneumoniae is an important atypical microorganism that causes community-acquired pneumonia (1). These atypical microorganisms are responsible for 7-20\% of community-acquired pneumonia cases, yet $\beta$-lactam agents are not effective against $M$. pneumoniae because it lacks a rigid cell wall. Currently, macrolides are considered as first line agents to treat atypical community-acquired pneumonia due to $M$. pneumoniae, while respiratory fluoroquinolones (such as levofloxacin), and tetracyclines are alternative treatment options (2). However, macrolide-resistant M. pneumoniae is growing globally and the prevalence rate shows variations across countries and regions. Epidemiologic studies have shown that the macrolide-resistant $M$. pneumoniae rate is between $0 \%$ and $15 \%$ in the United States of America, while reaching $100 \%$ in Asia, with resistance more dominant in low and middle-income countries (3).

Moreover, for some countries there has been little or no macrolide-resistant M. pneumoniae reporting, including the Islamic Republic of Iran, where studies determining the prevalence of community-acquired pneumonia due to $M$. pneumoniae and macrolide-resistant M. pneumoniae incidence remain scarce. Research by Arfaatabar et al. indicated that the frequency of $M$. pneumoniae among patients with atypical communityacquired pneumonia was reported to be high (4). Study by Noori et al. estimated the macrolide-resistant $M$. pneumoniae incidence to be almost $57 \%$ (5). In clinical practice, characteristics of macrolide-resistant $M$. pneumonia and macrolide-susceptible $M$. pneumonia are similar (6). In addition, polymerase chain reaction is not a routine diagnostic method for community-acquired pneumonia in some low and middle-income countries.

Perhaps for these reasons, most physicians are accustomed to prescribe levofloxacin as the first line empiric regimen in adults with atypical communityacquired pneumonia. Tuberculosis is common in the Region, thus the risk for the emergence of resistance to this valuable antibiotic exists if physicians use this agent inappropriately. Another aspect that is important to be clarified is the clinical relevance of macrolide-resistant M. pneumoniae in adults with community-acquired pneumonia. In the study by Cardinale et al. (7), which was done in a paediatric population, authors concluded alternative agents such as fluoroquinolones should be used if symptoms persist or in the case of clinical deterioration. According to another study by Lee et al. (6), the authors suggested that fluoroquinolones may be considered as an alternative agent when patients remain febrile or chest X-ray imaging shows deterioration at least 48-72 hours after macrolide initiation.

Detection of macrolide-resistant M. pneumoniae should be considered if patients did not respond to the macrolide regimen (6). However, an important point is to remind that macrolides are bacteriostatic (as opposed to fluoroquinolones that are bactericidal) and breakthrough infection might occur especially in those immunocompromised (8). Therefore, further evidence regarding these challenges is needed in low and middleincome countries. The conduct of well-designed studies to determine the prevalence of community-acquired pneumonia due to $M$. pneumoniae and macrolideresistant $M$. pneumoniae rate is emphasized. The minimal inhibitory concentration of antibiotics against $M$. pneumoniae can be determined in such studies, which is beneficial for clinical practice. These studies can also aim to assess the fluoroquinolone-resistant $M$. pneumoniae rate in an in-vitro situation, thus improving the selection of an appropriate antibiotic regimen according to in-vitro studies, clinical efficacy and related adverse effects.

\section{References}

1. Bartlett JG, Mundy LM. Community-acquired pneumonia. N Engl J Med. 1995 Dec 14;333(24):1618-24.

2. Waites KB, Xiao L, Liu Y, Balish MF, Atkinson TP. Mycoplasma pneumoniae from the respiratory tract and beyond. Clin Microbiol Rev. 2017 Jul 1;30(3):747-809. 
3. Pereyre S, Goret J, Bébéar C. Mycoplasma pneumoniae: current Knowledge on macrolide resistance and treatment. Front Microbiol. 2016;7:974. doi:10.3389/fmicb.2016.00974

4. Arfaatabar M, Aminharati F, Azimi G, Ashtari A, Pourbakhsh SA, Masoorian E, et al. High frequency of Mycoplasma pneumoniae among patients with atypical pneumonia in Tehran, Iran. Germs. 2018;8(3):126-133. doi:10.18683/germs.2018.1139.

5. Noori Goodarzi N, Pourmand MR, Arfaatabar M, Azimi G, Masoorian E, Rahimi Foroushani A, et al. First detection and characterization of macrolide-resistant Mycoplasma pneumoniae from people with community-acquired pneumonia in Iran. Microb Drug Resist. 2019 Sep 23. doi: 10.1089/mdr.2019.0223. [Epub ahead of print]

6. Lee H, Yun KW, Lee HJ, Choi EH. Antimicrobial therapy of macrolide-resistant Mycoplasma pneumoniae pneumonia in children. Expert review of anti-infective therapy. 2018;Jan 2;16(1):23-34.

7. Cardinale F, Chironna M, Chinellato I, Principi N, Esposito S. Clinical relevance of Mycoplasma pneumoniae macrolide resistance in children. J Clin Microbiol. 2013 Feb 1;51(2):723-4.

8. Alishlash AS, Atkinson TP, Schlappi C, Leal SM Jr, Waites KB, Xiao L. Mycoplasma pneumoniae carriage with de novo macrolide-resistance and breakthrough pneumonia. Pediatrics. 2019 Oct;144(4):e20191642. doi: 10.1542/peds.2019-1642. Epub 2019 Sep 5. 